\title{
Removal of Organic Pollutants from Wastewater Using a Lipophilic Substance: Cases of Isopropyl Myristate - Efficient and Increased Point-of-Use Versatility
}

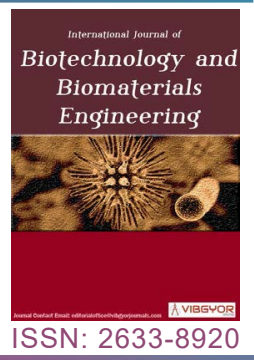

\section{Gamar $A^{1,2^{\star}}$, Zair $T^{1,2}$, El Kabriti $M^{3}$, MyrKues $S^{4,5}$, Hugland $K^{4}$ and El Hilali $F^{1,2}$}

${ }^{1}$ Research Team of Chemistry of the Bioactive Molecules and the Environment, Department of Chemistry, Faculty of Sciences, Moulay Ismail University, Morocco

${ }^{2}$ Laboratory of Chemistry of Materials and Biotechnology of Natural Products (Chima-Bio), Department of Chemistry, Faculty of Sciences, Moulay Ismail University, Morocco

${ }^{3}$ National Laboratory of the Studies and the Monitoring of the Pollution (NLSMP), Rabat, Morocco

${ }^{4}$ School of Natural Science, Linnaeus University, Kalmar, Sweden

${ }^{5}$ Department of Sanitary and Environmental Engineering, Rio de Janeiro State University-UERJ, Rio de Janeiro, Brazil

\begin{abstract}
The increasing frequency with which organic pollutants can be found in global surface water poses a formidable threat to both our environment and its creatures. While the problem has attracted adequate attention, current water treatment tools such as commercially available active carbon still cannot satisfy the remediating necessity due to its unfavorable rate of uptake and high regenerating cost. Moreover, water-insoluble pollutant adsorbents typically suffer from poor processability, effectively decreasing their potential for increased point-of-use versatility. Herein, we report a solution processable lipophilic ester-based material that readily undergoes simple coacervation upon ultrasonic solution processing. The experiments focused on the effect of the Isopropyl Myristate dosage and particle size on the removal efficiency for organic compounds. With a lipophilic ester dosage of $160 \mathrm{~g} \mathrm{~L}^{-1}$ and a particle size less than $1 \mathrm{~mm}$, the reductions of chemical oxygen demand (COD), biologic oxygen demand, and total organic carbon were $37( \pm 0.4), 24( \pm 0.4)$, and $30( \pm 0.3) \%$, respectively. Pre-treatment of lipophilic ester with hot water improved the COD removal efficiency by absorption from $37( \pm 0.4)$ to $42( \pm 1.6) \%$ when the same dosage $\left(160 \mathrm{~g} \mathrm{~L}^{-1}\right)$ was applied. Freundlich isotherm and pseudo-second-order kinetic models can explain sorption isotherm and sorption kinetics for COD using untreated lipophilic ester. Intra-particle diffusion model indicates that pore diffusion is not the rate-limiting step for COD removal. Based on the experimental data, lipophilic ester could be used as an alternative low-cost sorption media/filter for removal of organic compounds from real industrial wastewater.
\end{abstract}

\section{Keywords}

Isopropyl myristate, Sorption isotherm, Sorption kinetics, Lipophilic ester

\begin{abstract}
Abbreviations
IM: Isopropyl Myristate; AC: Activated Carbon; BOD: Biologic Oxygen Demand; COD: Chemical Oxygen Demand; TOC: Total Organic Carbon
\end{abstract}

*Corresponding author: A Gamar, Faculty of Sciences, Moulay Ismail University, BP 11201, 50000 Zitoune Meknes, Morocco

Accepted: December 12, 2020; Published: December 14, 2020

Copyright: (C) 2020 Gamar A, et al. This is an open-access article distributed under the terms of the Creative Commons Attribution License, which permits unrestricted use, distribution, and reproduction in any medium, provided the original author and source are credited.

Gamar et al. Int J Biotechnol Biomater Eng 2020, 2:004

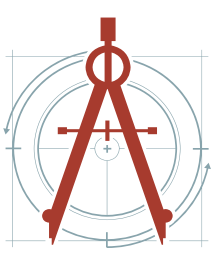




\section{Introduction}

The continued growth of intractable global water pollution has undoubtedly raised earnest concerns and the keen research interests of scientists all over the world. Resulting from the immoderate sluice of contaminated domestic, industrial, and agricultural water, organic pollutants, such as plastics and their components, pharmaceutical waste, and industrial dyes, can be found extensively in surface water [1-3]. Moreover, prior to being deemed suitable for industrial reuse and/or discharge to a centralized wastewater treatment plant, the pollutant concentration of as-generated raw industrial wastewater is extremely high and requires pretreatment. [4-7] Such is the case, for example, with industrial container and drum cleaning wastewater [4,5] and landfill leachates [8]. At this stage in wastewater treatment, electrocoagulation [4-7] and Fenton oxidation-based treatments $[4,6,7]$ are typically employed to decrease the chemical oxygen demand. Unfortunately, both methods suffer from the generation of a metal-laden sludge byproduct that requires further handling and disposal [4-7]. Fenton-based treatments also suffer from the high cost of hydrogen peroxide and the metal based homogeneous catalyst is not retained in the process $[4,6,7]$.

A single or several treatment technologies (biologic, chemical, and physicochemical treatment) can achieve the removal of organic pollutants from industrial wastewater. Among the conventional treatment options, sorption (adsorption and/or absorption) processes are found to be an effective method since it has high pollution removal capacity, having simple design and being easy to operate and maintain at full-scale. Commercial activated carbon $(A C)$ is regarded as an effective material for controlling the organic load. However, relatively high cost and sorbent losses from 10 to $15 \%$ during regeneration limit the use of $\mathrm{AC}$ by some industries. Recently, many authors [1-12] have intensively investigated environmental-friendly materials such as Isopropyl Myristate, agricultural wastes, sawdust, peat, bio-waste, and brick kiln ash for removal of organic pollutants and toxic metals from aqueous phase. The sorption efficiency of untreated Phoenix sylvestris sawdust to remove toxic metals, such as $\mathrm{Pb}$ and $\mathrm{V}$ from machinery cleaning wastewater increased from 32 to $99 \%$ for $\mathrm{Pb}$ and from 43 to $95 \%$ for $\mathrm{V}$ when the wastewater initial $\mathrm{pH}$ was re- duced from 7.4 to 4.0. Whereas $V$ removal was positively correlated with the adsorbent dose, $\mathrm{Pb}$ removal was not [9]; only a small part of it is recycled as forest fertilizer [13]. Disposal of large amounts of ashes per year will be more difficult due to increasing land cost and other constraints to build up new landfills. Since the physicochemical properties of wood ash are similar to commercial AC, it is possible to use lipophilic substance as an alternative low-cost carbon sorbent for wastewater pollution treatment. Lipophilic substance can remove metals $[14,15]$ as well as organic compounds from the aqueous solution. Color, COD, and lignin from pulp and paper wastewater were precipitated with calcium contained in lipophilic substance and were adsorbed on the surface of lipophilic substance particles [16]. Activated charcoal carbon from waste lipophilic could remove anionic surfactants, phenol and COD [17] from mechanized laundry and a plant for dry-cleaning and dyeing of cloths. Sorption of azo reactive dye onto lipophilic-shaving bottom ash fitted to a Freundlich isotherm [18].

To comply with the global sustainability policy towards zero dis-charge, waste utilization, and natural resource conservation and to contribute to the development of onsite low cost treatment options, this research aims to evaluate the sorption capacity of untreated lipophilic Substance (LS) to remove organic pollutants from machinery washing/cleaning wastewater generated at a lipophilic floor industry.

\section{Materials and Methods}

\section{Wastewater}

The wastewater used in the present study was collected on site, where the machinery used in gluing process of lipophilic-floor laminates is cleaned and washed regularly. Traditionally, daily cleaning wastewater has been stored in a small tank before diluting with drinking water and discharging into the municipal wastewater treatment plant. The wastewater contains aluminum sulfate, citric acid and a large number of unknown organic compounds. Wastewater samples were transported to the Laboratory of Linnaeus University, located 32 $\mathrm{km}$ away from the factory. The parameters monitored were temperature, $\mathrm{pH}$, and electrical conductivity (measured immediately after the samples arrived at the lab), total solids (TS), total suspended solids (TSS), COD, TOC, and BOD.

As a widely employed material for physical pol- 
lutant scrubbing, activated carbon (AC) is the most easily accessible adsorbent material for contaminated water treatment. However, activated carbon's poor removal of hydrophilic micropollutants [9-11] and high energy cost of regeneration [12,13] are limiting factors.

\section{Isopropyl myristate}

The Isopropyl Myristate (IM) is derived from Myristic Acid and isopropyl alcohol, and Butyl Myristate is derived from Myristic Acid and butyl alcohol. The CIR (Cosmetic Ingredient Review) Expert Panel concluded that Myristic Acid and its salts and esters were safe as a cosmetic ingredient in the present practices of use and concentration. It is a polar emollient and is used in cosmetic and topical medicinal preparations where good absorption into the skin is desired. Isopropyl myristate is being studied as a skin enhancer. It is also used as a pesticide against head lice, which works by dissolving the wax that covers the exoskeleton of head lice, killing them by dehydration [2]. It is used in the same way in flea and tick killing products for pets. It is used to remove bacteria from the oral cavity as the non-aqueous component of the two-phase mouthwash product "Dentyl pH".

Isopropyl myristate is also used as a solvent in perfume materials, and in the removal process of prosthetic make-up. Hydrolysis of the ester from isopropyl myristate can liberate the acid and the alcohol. The acid could be responsible for decreasing of the $\mathrm{pH}$ value of formulations $[3,4]$.

\section{Batch sorption tests}

We used a cosmetic composition based on Isopropyl myristate in the form of a compact powder solid fat for make-up and/or skin care, (reference du produit: EP 1559394 A1).

The sorption experiments were performed in batch mode using $500 \mathrm{~mL}$ flasks and agitation speed at $600 \mathrm{rpm}$ with time intervals for sampling at 5, 10, $20,30,45,60,90$, and $120 \mathrm{~min}$. The effect of IM concentration was investigated in a range of 20-160 g $\mathrm{L}^{-1}$ with cleaning/washing wastewater containing $40650 \mathrm{mg} \mathrm{L}^{-1}$ of COD (see details in Table 1). Different IM particle sizes $(<0.5,<1$, and $1-2 \mathrm{~mm}$ ) were generated by prilling technology coupled with $-30^{\circ} \mathrm{C}$ cooling, using prilling equipment (Spherisator $\mathrm{M}, \mathrm{BRACE}$ - GmbH, Linnaeus University, Kalmar, Sweden) consisting of two cooling systems: a thermostatized liquid bath $\left(25\right.$ to $5^{\circ} \mathrm{C}$ ) or an air cooling tower (up to $\left.-30^{\circ} \mathrm{C}\right)$. The particles were also tested for determining the reduction of COD and TOC using IM dosage of $160 \mathrm{~g} \mathrm{~L}^{-1}$ compared to the activated wood carbon (CAS: 7440-44-0, 1.02184; MERCK). All the experiments were performed in duplicate at room temperature $\left(20-28{ }^{\circ} \mathrm{C}\right)$. The samples were withdrawn from the flask at predetermined time intervals and filtrated with $0.45 \mathrm{~mm}$ filter paper (GF/C Whatman) before COD, BOD, and TOC were analyzed.

The effect of isopropyl myristate pre-treatment in the pollutants removal efficiency: Coagulation/ flocculation/emulsification followed by precipitation after a settling time was suspected to be involved to some extent in the reduction of COD during sorption tests, as a result of the presence of aluminum sulfate $\mathrm{Al}_{2}\left(\mathrm{SO}_{4}\right)_{3}$ (a well-known coagulant) in the studied wastewater. To assess the relative contribution of coagulation/flocculation process and carbon sorption process, a laboratory test was conducted. The pollutants removal efficiency achieved by unwashed-IM was compared to the one achieved by washed-IM. IM (200 g) was washed with hot water at liquid/solid (L/S) ratio of $5: 1$ by boiling the sample at $98{ }^{\circ} \mathrm{C}$ for $1 \mathrm{~h}$. The solution obtained after boiling was collected for further use in a coagulation - precipitation test. The boiled IM was then washed several times with distilled water until the $\mathrm{pH}$ of the solution remained constant and then, dried at $108{ }^{\circ} \mathrm{C}$ for 1 day and kept in the airtight chamber. The test to assess the COD and TOC removal efficiency by washed-IM was carried out using $160 \mathrm{~g} \mathrm{~L}^{-1}$ of IM under the same above-described conditions for batch sorption test.

The washing water obtained after boiling the Isopropyl Myristate was added to the wastewater

Table 1: Characteristics of the studied cleaning wastewater from the wood floor industry.

\begin{tabular}{|l|l|l|}
\hline Parameters & Unit & Mean \pm SD \\
\hline $\mathrm{pH}$ & - & $1.40 \pm 0.04$ \\
\hline Conductivity & $\mathrm{mS} \mathrm{cm}^{-1}$ & $32.65 \pm 0.78$ \\
\hline TSS & $\mathrm{g} \mathrm{L}^{-1}$ & $13.7 \pm 13.80$ \\
\hline Turbidity & $\mathrm{NTU}$ & $2289.42 \pm 271.62$ \\
\hline TS & $\mathrm{g} \mathrm{L}^{-1}$ & $101.36 \pm 27.06$ \\
\hline TOC & $\mathrm{mg} \mathrm{L}^{-1}$ & $21600 \pm 2687$ \\
\hline BOD & $\mathrm{mg} \mathrm{L}^{-1}$ & $15001 \pm 2406$ \\
\hline COD & $\mathrm{mg} \mathrm{L}^{-1}$ & $40650 \pm 4412$ \\
\hline COD/BOD & - & $3.29 \pm 0.006$ \\
\hline
\end{tabular}


in different proportions $(75,50$, and $25 \%)$. The suspensions were stirred at $600 \mathrm{rpm}$ for $5 \mathrm{~min}$ when the speed was slowed down to $120 \mathrm{rpm}$ for $30 \mathrm{~min}$. The reaction between oxides and organic load was allowed to take place during $60 \mathrm{~min}$, when the sample was filtrated for COD and TOC analysis was found to be completely insoluble in water. However, IM it was discovered that upon ultrasonic treatment $[17,18]\left(5 \mathrm{mg} \mathrm{mL}^{-1}\right)$ underwent simple coacervation $[19,20]$.

Freundlich isotherm: In order to understand the sorption capacity of IM, the experimental data was modeled by fitting to Freundlich isotherm, which assumes that the sorption is under heterogeneous surface conditions [19]. The linear equation of Freundlich isotherm is given by Eq. (1):

$$
\log q_{e}=\log K+\frac{1}{n}\left(\log C_{e}\right)
$$

Where $q_{e}\left(m g^{-1}\right)$ is the amount of COD adsorbed per unit of sorbent at equilibrium and $\mathrm{C}_{\mathrm{e}}$ ( $\mathrm{mg} \mathrm{L}^{-1}$ ) is the equilibrium COD concentration. $1 / \mathrm{n}$ and $\mathrm{K}$ in the Freundlich equation are constants related to the sorption capacity and the energy sorption, respectively.

Pseudo-second order sorption kinetics: The model is used to explain sorption rate in the system as a chemical phenomenon [20]. The linear equation of pseudo-second-order is expressed in Eq. (2):

$$
\frac{t}{q_{t}}=\frac{1}{k_{2} q_{e}^{2}}+\frac{1}{q_{e}} t
$$

Where $\mathrm{k}_{2}\left(\mathrm{~g} \mathrm{mg}^{-1} \mathrm{~min}^{-1}\right)$ is the rate constant of the second-order adsorption; $\mathrm{q}_{\mathrm{e}}\left(\mathrm{mg} \mathrm{g}^{-1}\right)$ and $\mathrm{q}_{\mathrm{t}}(\mathrm{mg}$ $\left.\mathrm{g}^{-1}\right)$ represent the amount of COD adsorbed on IM, at equilibrium and at time $t$, respectively. The variables $\mathrm{q}_{\mathrm{e}}$ and $\mathrm{k}_{2}$ are calculated from the slope and $y$-intercept by plotting the function in Eq. (2).

Intra-particle diffusion kinetics: Intra-particle diffusion kinetic (Eq. (3)) were also studied in order to understand the mechanism of COD removal by $\mathrm{IM}$ and to identify the rate-limiting step of sorption process [21,22]:

$$
q_{t}=k_{i d} t^{1 / 2}+C
$$

Where $\mathrm{k}_{\mathrm{id}}\left(\mathrm{mg} \mathrm{g}^{-1} \mathrm{~min}^{1 / 2}\right)$ is the intra-particle diffusion rate constant.

\section{Leaching tests}

The potential release of secondary pollutants such as toxic metals from IM was investigated according to the Swedish Standard for leaching test (SS-EN 12457-2:2002) [23]. L/S at 5 and 10 were per-formed using distilled water and orbital shaking in water bath (OLS 200, Grant) for $24 \mathrm{~h}$ at temperature of $2028^{\circ} \mathrm{C}$. Twelve trace metals in wood leachate were determined by the national laboratory of the Studies and the Monitoring of the Pollution in Morocco.

\section{Analytical methods}

Solid content including TS and TSS were determined according to the Standard Methods Handbook [24] with equipment that is part of the material means of Linnaeus University, Kalmar, Sweden. BOD analysis was performed by a modification of ISO 5815 [25]. COD and TOC were analyzed by extraction method using Thermo reactor LT 100-1 Dr. Lange for digestion of the samples and Spectrophotometer XION $500 \mathrm{Dr}$. Lange for colorimetric determination (ref: 91/271/CEE).

\section{Results and Discussion}

\section{Physicochemical characteristics of the studied wastewater}

The cleaning wastewater has very high organic load, which is moderately biodegradable [26] as indicated by a COD/BOD ratio of 3.29. At higher COD/ $B O D$ ratios, the microorganisms require longer time to degrade the organic compounds, resulting in a longer retention time and larger area requirement for construction of a biologic treatment plant. Additionally, very low $\mathrm{pH}$ in the wastewater can cause corrosion in the pipe system and also create unsuitable condition for biologic wastewater treatment processes.

\section{Batch sorption tests}

Effect of contact time: The effect of the contact time on COD removal was studied with two different IM dosages (40 and $160 \mathrm{~g} \mathrm{~L}^{-1}$ ), as shown in Figure 1. The percentage of COD removal increased with time. About $30 \%$ of the initial COD were rapidly removed within $5 \mathrm{~min}$ at both adsorbent dosages. The equilibrium of COD removal in both cases was attained after 20 min, being the maximum removal of $30 \%$ with the sorbent dosage of $40 \mathrm{~g} \mathrm{~L}^{-1}$ and $37 \%$ with the sorbent dosage of $160 \mathrm{~g} \mathrm{~L}^{-1}$. Higher COD sorption rates at the beginning of the treatment may be due to the large number of surface adsorption sites available to capture pollutants from the solution. 


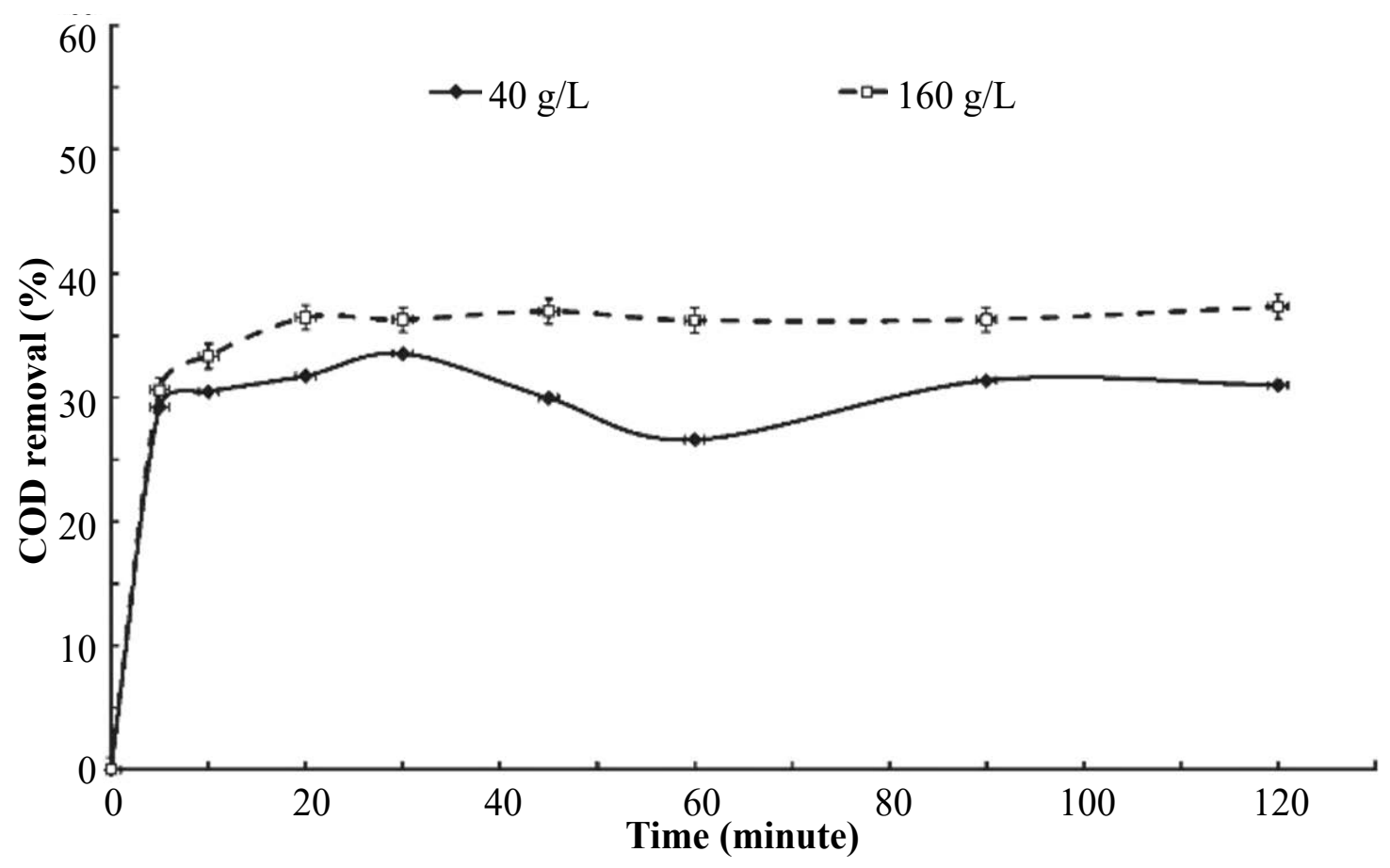

Figure 1: Effect of contact time on COD reduction in the cleaning/washing wastewater by Isopropyl Myristate. Initial COD concentration: $40650 \mathrm{mg} \mathrm{L}^{-1}$. Initial pH of the wastewater with no correction: 1.37. Agitation speed: $600 \mathrm{rpm}$. Isopropyl Myristate particle size: $<1 \mathrm{~mm}$ (bars $1 / 4$ SD).

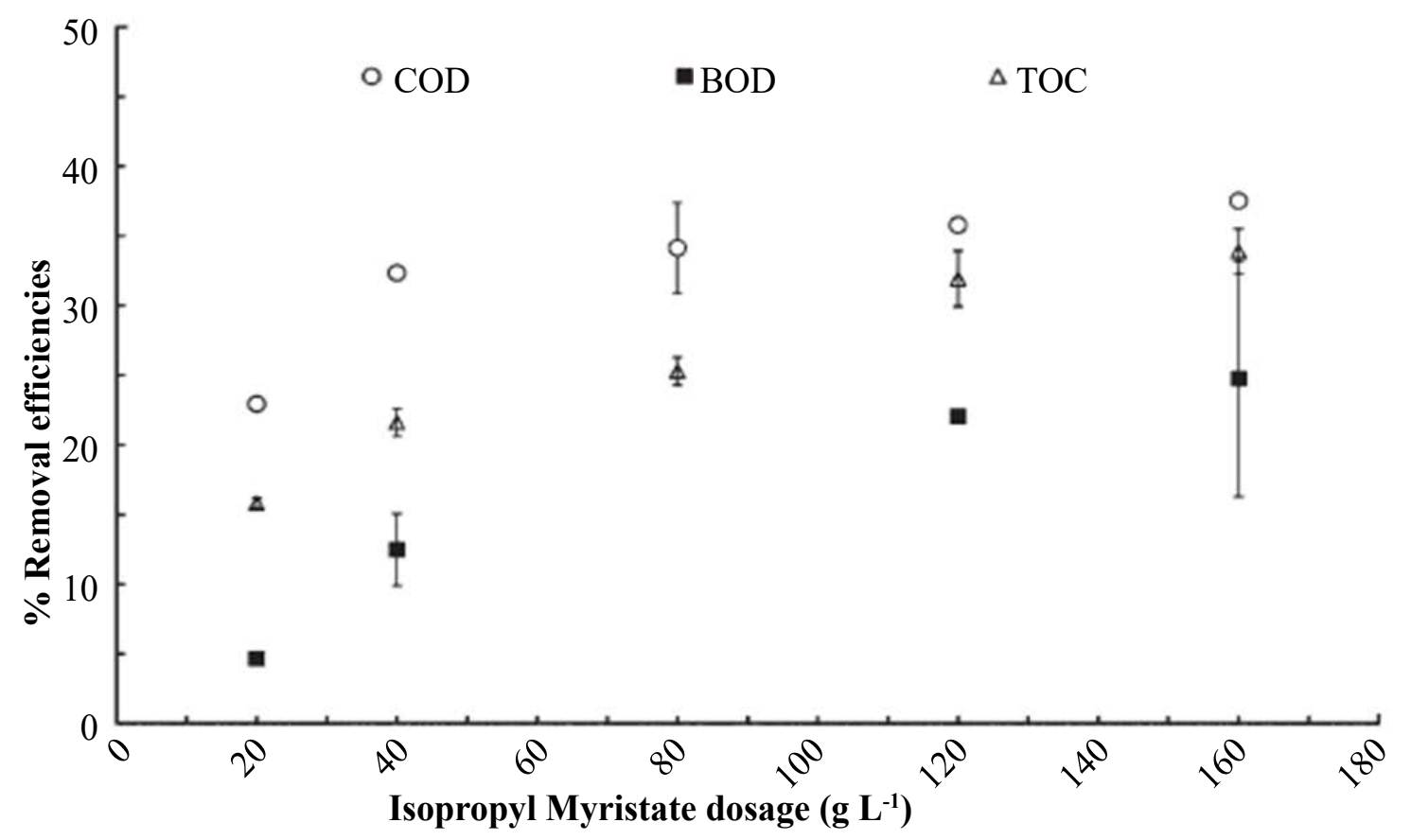

Figure 2: Effect of Isopropyl Myristate dosage on the COD, TOC, and BOD removal efficiencies (bars $1 / 4$ SD).

Effect of the isopropyl myristate dosage: The effect of IM dosage on the COD, TOC, and BOD removal efficiency is presented in Figure 2. When the IM dosage increased from 20 to $160 \mathrm{~g} \mathrm{~L}^{-1}$, the percentage of $C O D, T O C$, and BOD removal increased from 23 to $37 \%, 15$ to $30 \%$, and 4 to $24 \%$, respectively. The results indicate that COD removal from the wastewater is related to the amount of IM. At higher sorbent dosage, the greater is the surface area and the carbon content, resulting in higher 
COD sorption [2-4,27]. The COD removal efficiency achieved in this experiment was comparable to the one obtained with black wood ash used for treating pulp and paper wastewater [16] and relatively higher than the efficiency of bagasse AC for removing phosphoric acid from wastewater [28].

As a consequence of the higher percentage removal of COD than BOD and TOC, the COD/BOD ratio in the wastewater after treatment with $I M$ at dosage of $160 \mathrm{~g} \mathrm{~L}^{-1}$ decreased from 3.31 .2 to 2.4 0.1 .

This change indicates that IM had a higher impact on removal of non-biodegradable materials compared to biodegradable materials. Therefore, it is feasible to use low-cost IM filter as a pre-treatment process for subsequent biologic treatment.

Development of $\mathrm{pH}$ : During the treatment of industrial wastewater with IM it was observed a fast and sharp increase of $\mathrm{pH}$ in the aqueous phase during the first 5 min of contact time, being the degree of increase positively related to the IM dosage. The $\mathrm{pH}$ increased from 1.37 to $1.95,2.24,5.3$, 6.5, and 7.1 after agitation for 5 min with IM dosages of $20,40,80,120$, and $160 \mathrm{~g} \mathrm{~L}^{-1}$, respectively. However, after 20 min of contact time, the $\mathrm{pH}$ of the aqueous phase remained stable for low dosages ( 20 and $40 \mathrm{~g} \mathrm{~L}^{-1}$ ) and had only slight and very slow increase for higher dosages $(80,120$, and 160 $\left.\mathrm{g} \mathrm{L}^{-1}\right)$. The ability of IM to neutralize the $\mathrm{pH}$ of acid waters is due to the dissolution of calcium (Ca), potassium (K), and Magnesium (Mg) present in IM [18]. Saritpongteeraka, et al. [29] confirmed that isopropyl myristate can be used for $\mathrm{pH}$ adjustment for treating acid wastewater with the advantage that it does not deteriorate the performance of an anaerobic baffled reactor.

COD removal by treated and untreated isopropyl myristate: Figure 3 illustrates the reduction of COD and TOC by washed-IM compared to unwashed-IM in a batch sorption system with IM concentration of $160 \mathrm{~g} \mathrm{~L}^{-1}$. When using the washed Isopropyl Myristate, the COD and TOC removal efficiencies were $42( \pm 1.6)$ and $32( \pm 2.2) \%$, respectively. When using unwashed Isopropyl Myristate, the COD and TOC removal efficiencies were $37( \pm 0.7)$ and $30( \pm 3.3) \%$, respectively. A slightly lower removal efficiency obtained with unwashed-IM may be due to the dissolution of impurities in the wastewater, which were attached on the IM-particles to the solution. These substances are likely to compete later on with the pollutants for the sorption sites, resulting in lower pollutants reduction [9]. Although, washed Isopropyl Myristate had higher removal efficiency, since the difference was not very high, the cost-effectiveness of Isopropyl Myristate pretreatment is a question mark to be considered for large scale implementation.

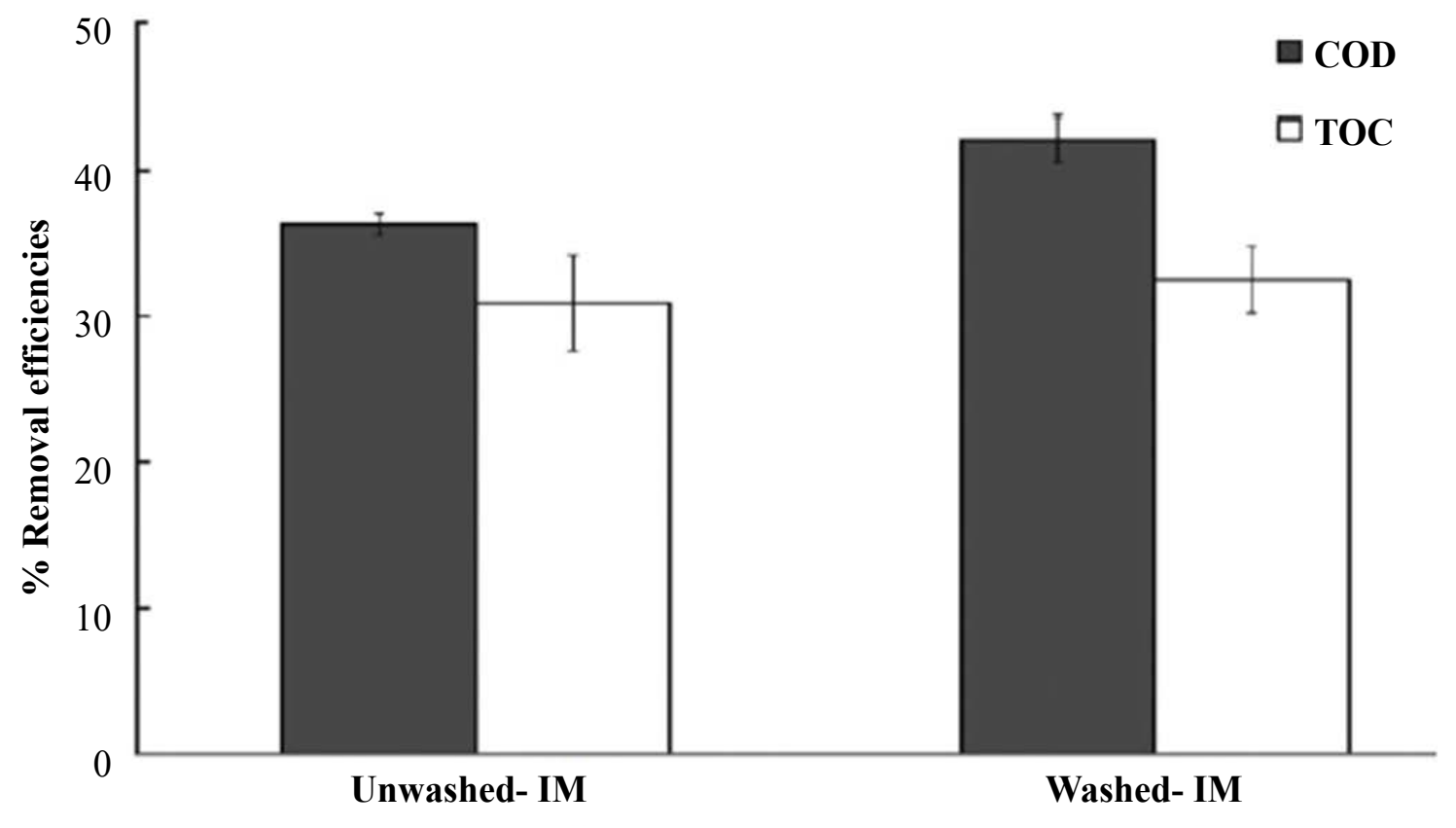

Figure 3: Comparison of COD and TOC removal using-unwashed Isopropyl Myristate (unwashed-IM) and washed- Isopropyl Myristate (washed-IM) (bars $1 / 4$ SD). 


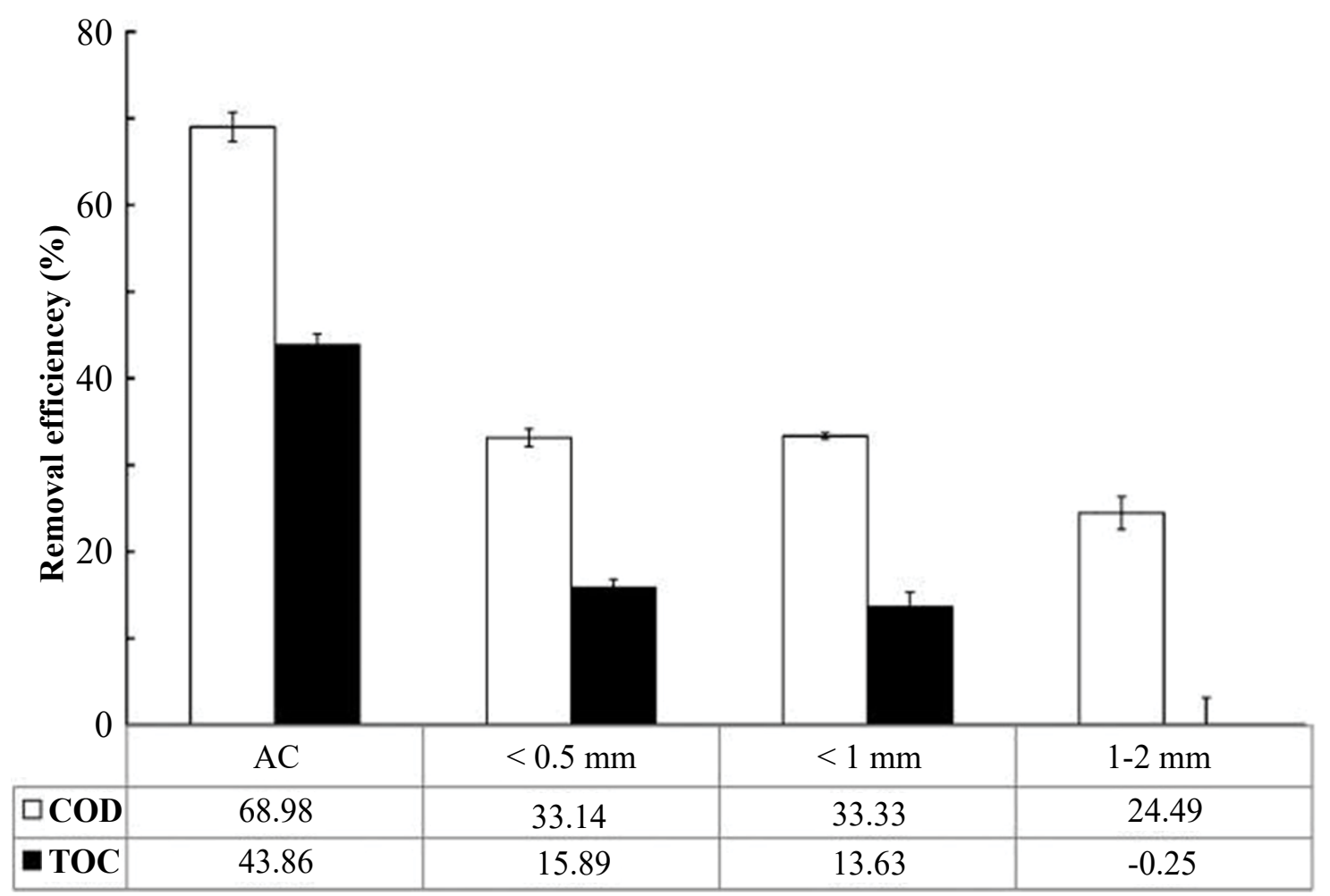

Figure 4: Removal efficiencies of COD and TOC after sorption tests with Isopropyl Myristate with different particle size ranges, compared to commercial activated carbon (AC) with sorbent concentration of $120 \mathrm{~g} \mathrm{~L}^{-1}$ (bars $1 / 4 \mathrm{SD}$ ).

The studied cleaning wastewater has aluminum sulfate $\left(\mathrm{Al}_{2}\left(\mathrm{SO}_{4}\right)_{3}\right)$, which is used in the gluing process during wood-floor production. When the Isopropyl Myristate particles are in contact with the wastewater, alkaline oxides ( $\mathrm{CaO}, \mathrm{MgO}$, and $\mathrm{K}_{2} \mathrm{O}$ ) are released to the solution, having consequently, an increase in the $\mathrm{pH}$ of solution to 5-8. Under these conditions, the alum in the wastewater might be effective in coagulating pollutants in the wastewater treatment plant. In order to assess the COD and TOC removal from the wastewater due to coagulation/flocculation reactions, the water produced after washing IM with hot water $\left(958^{\circ} \mathrm{C}\right)$ at L/S ratio of $5: 1$ for $1 \mathrm{~h}$ was stirred with the wastewater at different percentages of 25,50 , and $75 \%$. However, the results in the present study revealed that no reduction of COD was observed when the cleaning wastewater was kept in contact with wood ash leachate. This may be because the alum in the wastewater was not able to remove soluble organic material. Fan, et al. [30] reported that complex coagulant produced from Isopropyl Myristate could not remove soluble COD from industrial wastewater.
Effect of wood isopropyl myristate particle size: It has been reported that removal efficiencies for organic compounds increase with decreasing of the sorbents particle size [3-5]. In this experiment (Figure 4), the removal efficiencies increased from $24.5( \pm 0.6)$ to $33.3( \pm 2.1) \%$ for COD and from 0 to 15.9 ( \pm 0.2$) \%$ for TOC by decreasing the IM particle size from 1-2 to $<1 \mathrm{~mm}$. However, no difference in removal efficiency of COD and TOC has been found between the IM particle size $<1$ and $<0.5 \mathrm{~mm}$. This may be due to the fact that sorbent preparation with particle $<1 \mathrm{~mm}$ contains particles $<0.5 \mathrm{~mm}$ as well.

Although untreated IM has less efficiency for reduction of COD and TOC, compared to the commercial AC as shown in Figure 4, further development of IM (classified as waste) as a low-cost material alternative for wastewater treatment can be seen as an attractive strategy particularly due to waste availability and waste utilization.

\section{Sorption isotherm and sorption kinetics}

Freundlich isotherm: Figure 5 shows the equilibrium sorption isotherm following Freundlich Eq. 


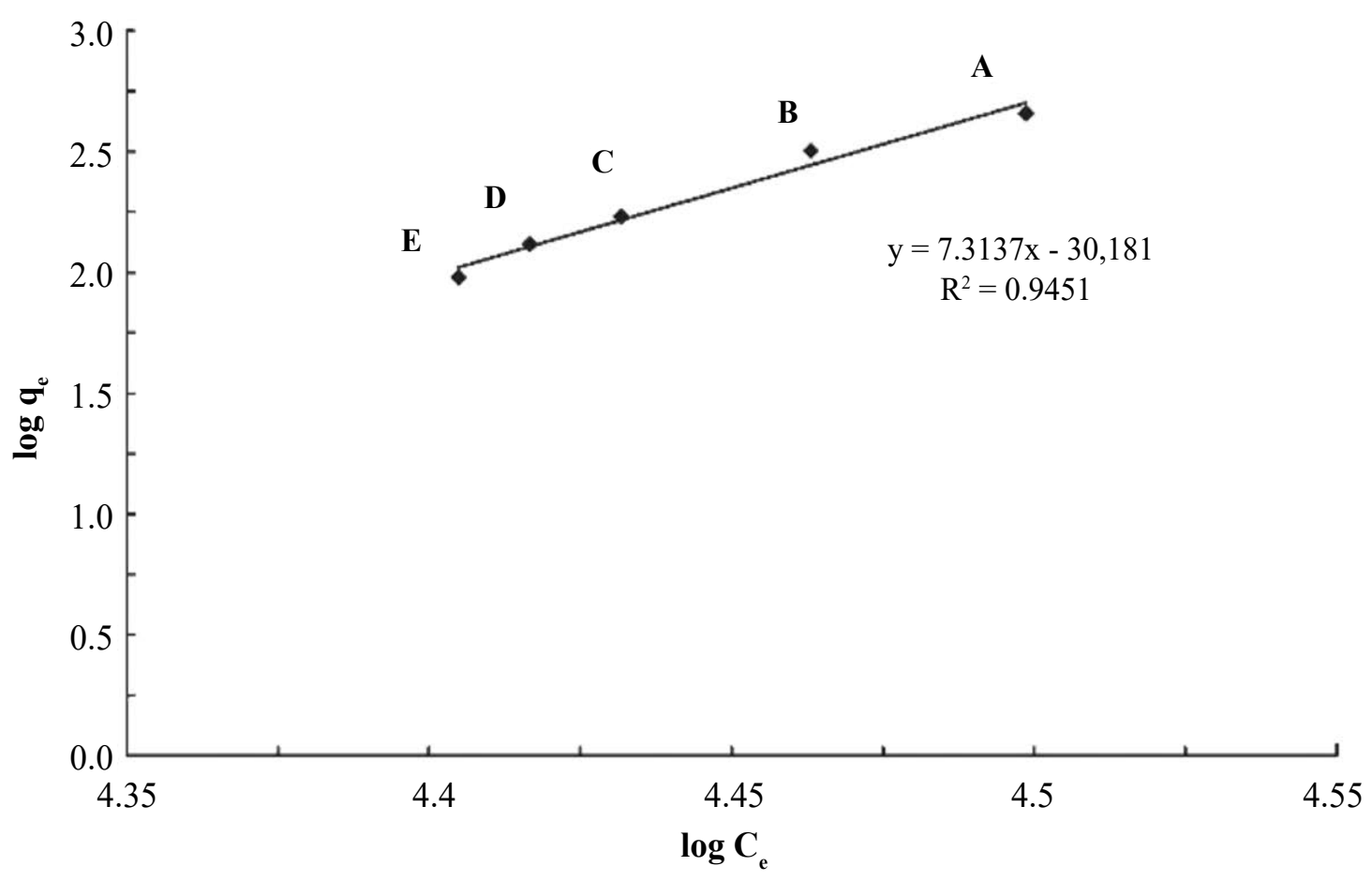

Figure 5: Freundlich isotherm of COD removal by Isopropyl Myristate particle size $<1 \mathrm{~mm}$ ), isopropyl myristate

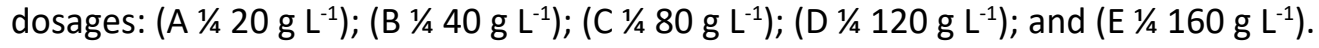

(1) for COD removal at different IM concentrations of $20,40,80,120$, and $160 \mathrm{~g} \mathrm{~L}^{-1}$. The Freundlich parameters " $n$ " and " $K$ " can be calculated from the plot of $\log q_{e}$ against $\log C_{e}$ and the values refer to the adsorption intensity ( $\mathrm{n}$ ) and adsorption capacity (K), respectively. According to Febrianto, et al. [31] and Hamdaoui, et al. [32], the value of " $n$ " gives an indication of the adsorption favorability. It is generally stated that values of " $n$ " in the range 2-10 represent well, 1-2 moderate, and less than 1 poor adsorption performance. In this experiment, it was observed that the experimental data fitted to the model with a high $\mathrm{R}^{2}$-value (0.9451). This indicated that the Freundlich model is a good description of the kinetics of COD removal by IM (Figure 5). The " $n$ " value of 0.14 (as $1 / n$ equal to 7.31 ) was low in comparison to " $n$ " values obtained with sorption of COD by commercial AC, which is usually reported within the range of 2.5-1.0 [2,3,33]. Although the low value of " $n$ " indicates that the wood ash tested had less affinity to adsorb the organic pollutants in the wastewater treated, $37 \%$ of average COD removal efficiency at $160 \mathrm{mg} \mathrm{L}^{-1}$ of wood ash was achieved. Hinz [34] suggested two reasons that cause $\mathrm{n}<1$, including: (i) Cooperative adsorption due to solute-solute attractive forces at the surface and (ii) Competition reaction of pollutants in the complex wastewater and IM. Similar trends of adsorption isotherm are reported in other studies $[10,27,35]$.

Pseudo-second order sorption kinetic: The rate of COD removal was plotted against the contact time according to the pseudo-second-order-kinetics model. The equilibrium of COD sorbed onto Isopropyl Myristate, the $\mathrm{q}_{\mathrm{e}}$ and $\mathrm{k}$, were calculated from the slope and $y$-intercept obtained from Figure 6. As expected, when the mass of IM was increased from 40 to $160 \mathrm{~g} \mathrm{~L}^{-1}$, the rate constant $(\mathrm{k})$ of COD removal increased from 0.0114 to 0.0170 $\mathrm{mg} \mathrm{g}^{-1} \min ^{0.5}$.

This can be attributed to the fact that increasing sorbent mass for a constant sorbate concentration increased the surface area and available sorptive sites for COD sorption. On the other hand, the $q_{e}$ value was found to decrease from 312 to $95 \mathrm{mg} \mathrm{g}^{-1}$ with the increase of isopropyl myristate concentration from 40 to $160 \mathrm{~g} \mathrm{~L}^{-1}$. A similar trend of sorption kinetics was found in previous studies [9,36,37]. It is therefore, clear that the equilibrium sorption capacity of COD is a function of wood ash concentration.

Generally, the pseudo-second-order kinetic was the best model to describe sorption mechanism of 


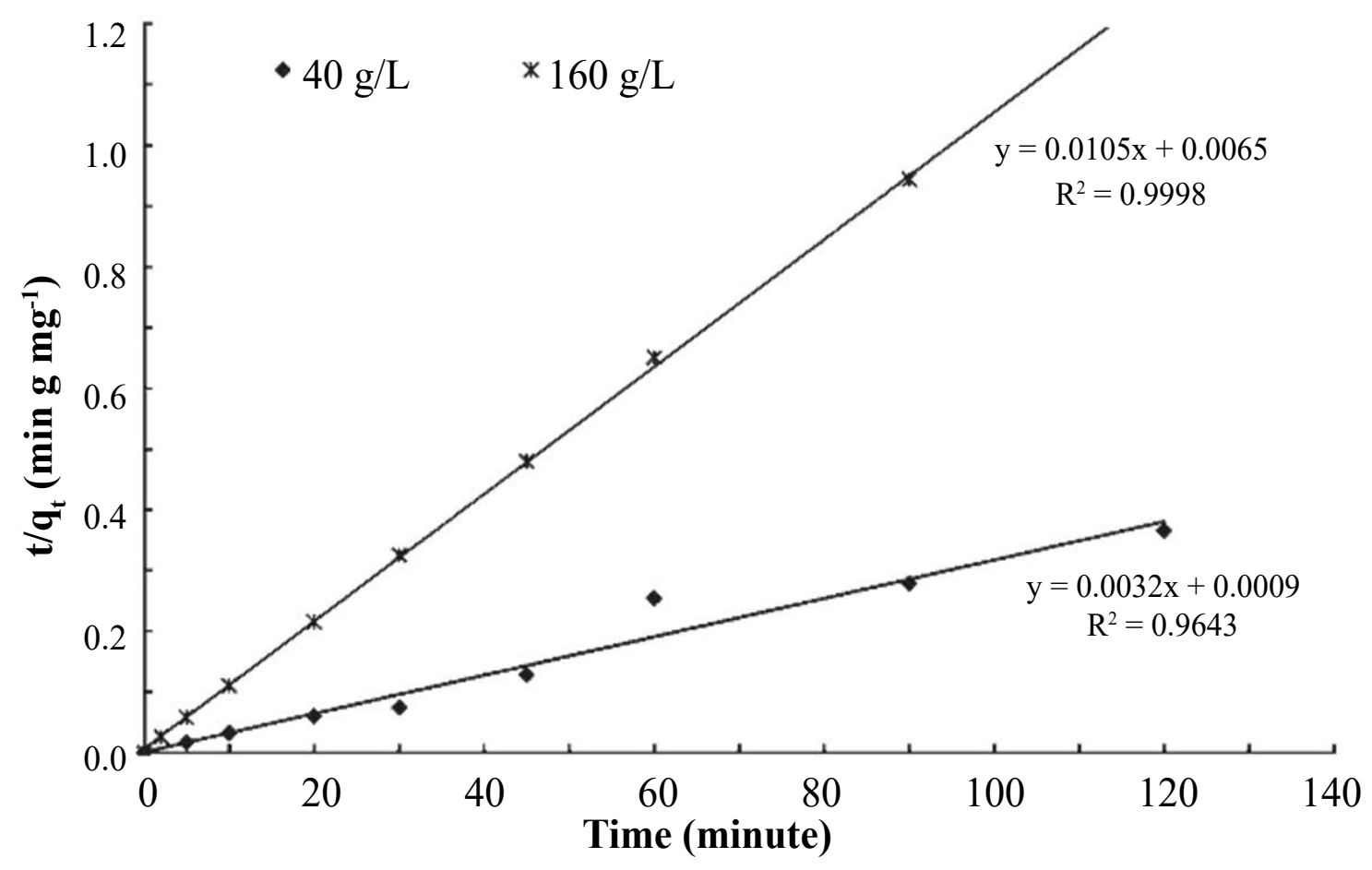

Figure 6: Pseudo-second order sorption kinetic of COD on Isopropyl Myristate in two dosages (40 and 160 $\left.\mathrm{g} \mathrm{L}^{-1}\right)$.

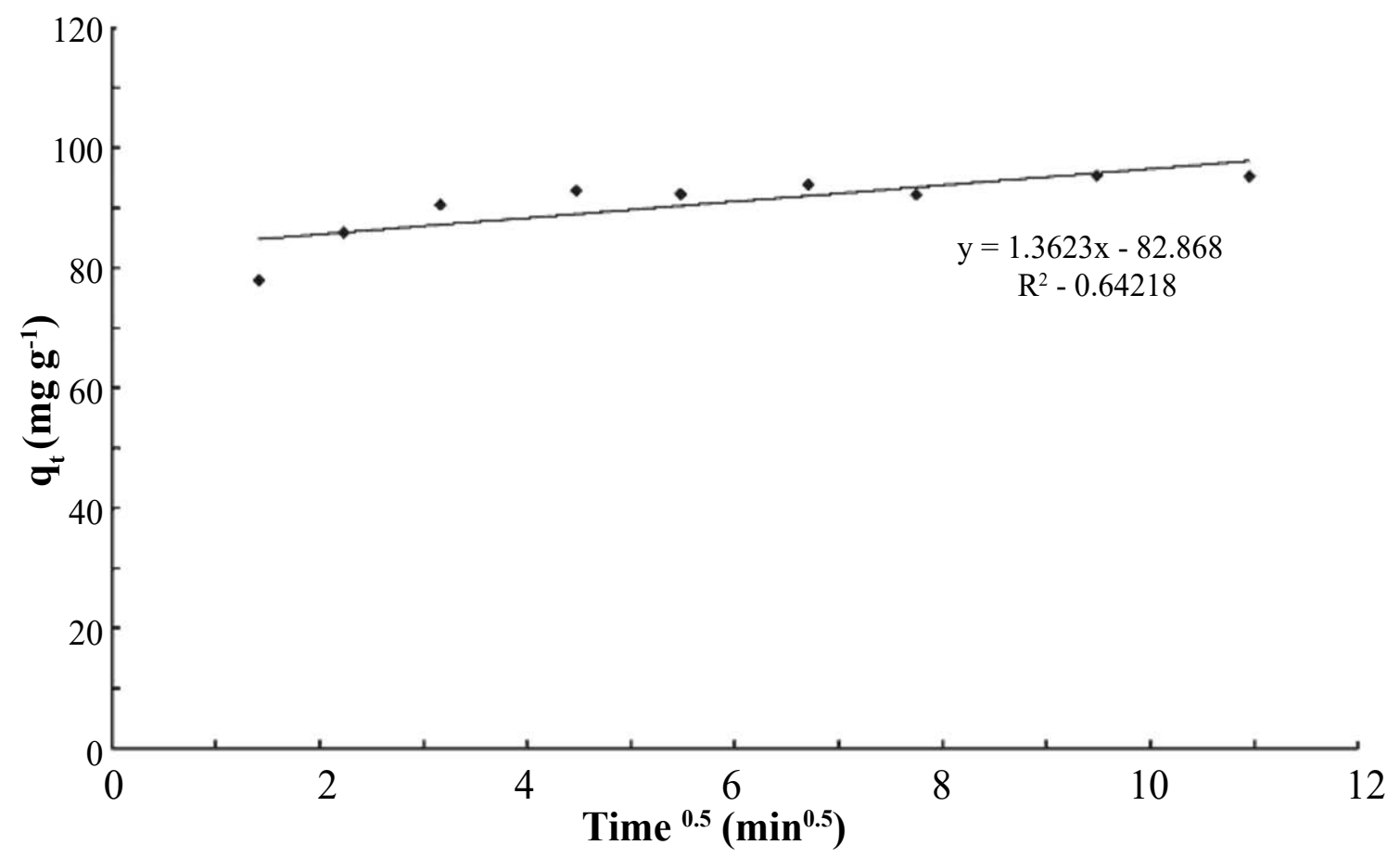

Figure 7: Intra-particle diffusion kinetics for COD removal with Isopropyl Myristate (particle size $<1 \mathrm{~mm}$ ).

COD by IM, as illustrated by high coefficients of determination $\left(R^{2}\right)$ at 0.9998 and 0.9643 for 40 and $160 \mathrm{~g} \mathrm{~L}^{-1}$, respectively. The results suggest that the COD sorption involved chemisorption processes [27].
Intra-particle diffusion kinetics: To confirm the diffusion of pollutants within the pore of solid phase, the experimental data of COD removal by different IM concentrations were fitted in the intra-particle diffusion models (Eq. (2)). It has been 


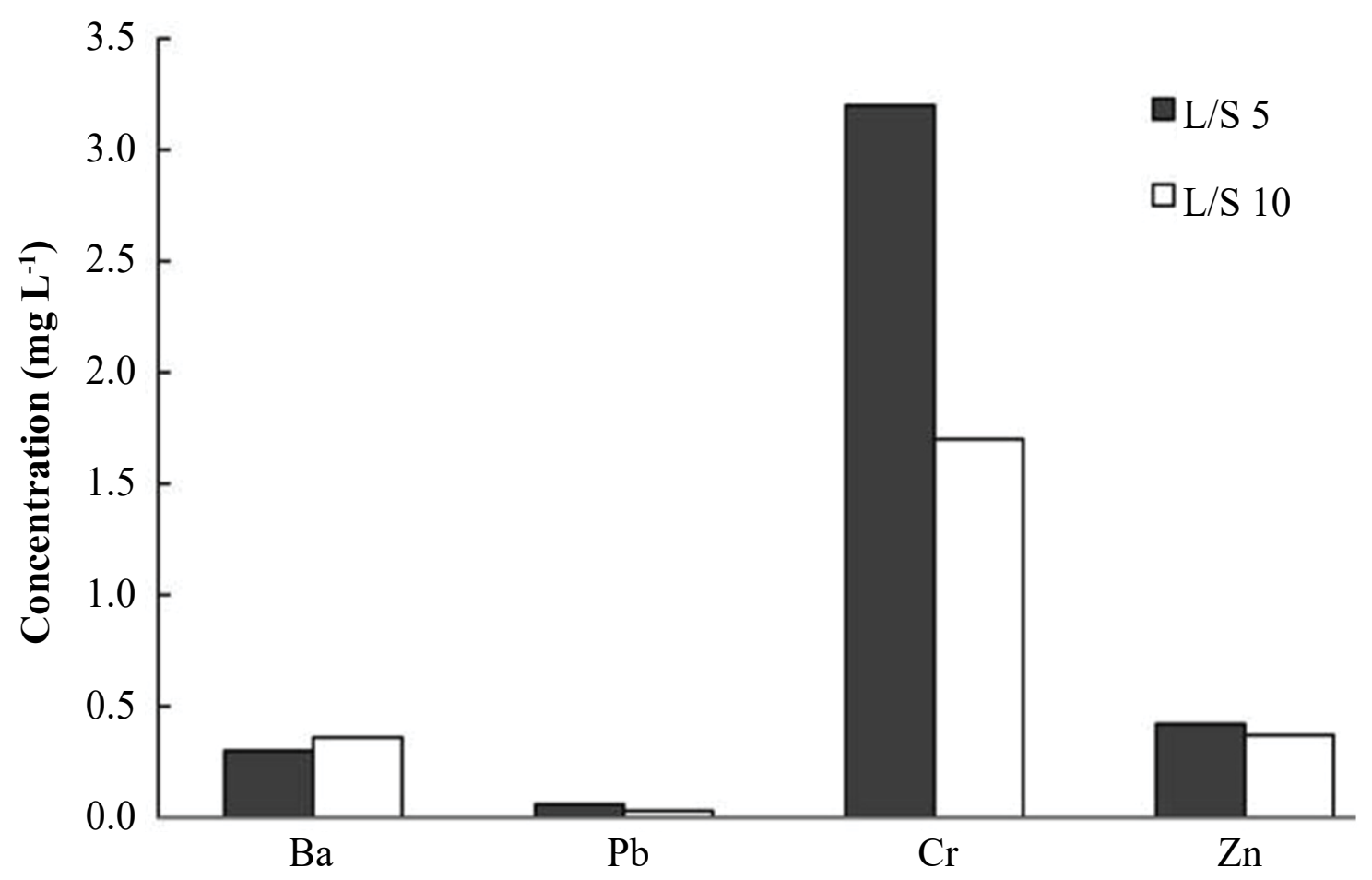

Figure 8: Metals concentrations in the water after leaching tests with Isopropyl Myristate under two L/S ratios (5 and 10).

described [38] that the plot of $q_{t}$ versus $t^{1 / 2}$ should be a straight line with a slope $\mathrm{k}_{\mathrm{id}}$ and intercept $\mathrm{C}$ when the adsorption mechanism follows the intra-particle diffusion process. The slope representing intra-particle diffusion rate constant and $y$-intercept is proportional to the boundary layer thickness. In the adsorption system, the boundary layer is considered as a viscous drag existing between the adsorbent surface and the pollutants in solution diffusing across its surface. At a higher value of $C$, the system depicts higher adsorption capacities or it can be said that the larger the intercept, the greater the contribution of the surface sorption in the rate-limiting step [35]. As shown in Figure 7, the COD adsorbed per mass unit of IM in the present study did not vary proportionally with contact time $\left(t^{1 / 2}\right)$. The intra-particle diffusion rate constant $\left(k_{i d}\right)$ was found at $1.36 \mathrm{mg} \mathrm{g}^{-1} \mathrm{~min}^{0.5}$, which is comparable to the studies of Mall, et al. [38] and Palanisamy and Sivakumar [39]. However, the value of y-intercept ( $83 \mathrm{mg} \mathrm{g}^{-1}$ ) obtained in this study was higher than those presented in the refereed literature. This suggests that the sorption mechanism of COD by IM was partially controlled by pore diffusion.

\section{Leaching test}

In this experiment, twelve trace metals (As, Ba,
$\mathrm{Cd}, \mathrm{Co}, \mathrm{Cr}, \mathrm{Cu}, \mathrm{Fe}, \mathrm{Hg}, \mathrm{Ni}, \mathrm{Pb}, \mathrm{V}$, and $\mathrm{Zn}$ ) leaching from IM with two different $L / S$ ratios (5 and 10 ) were measured. The results (Figure 8 ) show that chromium $(\mathrm{Cr})$ had the highest concentration in the isopropyl myristate leachate followed by zinc $(\mathrm{Zn})$, barium $(\mathrm{Ba})$, and lead $(\mathrm{Pb})$ in this order. The concentrations of other toxic metals were found to be relatively low $\left(<0.005 \mathrm{mg} \mathrm{L}^{-1}\right)$ for both tested $\mathrm{L} / \mathrm{S}$ ratios. Leachability of trace metals from isopropyl myristate was higher when the sorbent was washed with a lower $\mathrm{pH}$ solution (results not shown in this paper). The reason for the presence of $\mathrm{Cr}$ in relatively high concentrations in the present study is not clear. In general, $\mathrm{Cr}$ is a minor constituent in isopropyl myristate, although it may be added when the coal is used as a co-combustion fuel in the heating plant or due to the application of inorganic wood preservatives that contain chromates as fixative $[40,41]$. During the combustion process, $\mathrm{Cr}$ is oxidized to hexavalent $\mathrm{Cr}(\mathrm{VI})$, which can be dissolved in the liquid phase. $\mathrm{Cr}(\mathrm{VI})$ is known as toxic and carcinogenic element [40].

Therefore, the disposal of Isopropyl Myristate in landfill is restricted and only allowed when the $\mathrm{Cr}$ in leachate does not exceed $0.05 \mathrm{mg} \mathrm{L}^{-1}$ [41]. In sorption processes, the trace metals released from the 
Isopropyl Myristate are considered as impurity that can interfere in the adsorption process. To minimize the risk of releasing high concentrations of $\mathrm{Cr}$ and other trace metals from the IM into the liquid phase, it is suggested to wash IM several times with distilled water or an acid solution before using it as sorbent material for wastewater treatment. Liodakis, et al. [42] revealed that washing isopropyl myristate (Mediterranean forest species) with a solution with $\mathrm{pH} 6.0$, removed $95 \%$ of $\mathrm{Cr}$.

\section{Conclusion}

Isopropyl Myristate can be used as a low-cost sorbent/filter for removal of organic compounds from industrial wastewater. The experimental results showed the removal efficiencies for COD, $B O D$, and TOC depend on the quantity of IM and its particle size. The average removal efficiencies were found to be $37( \pm 0.4) \%$ for COD, $24( \pm 0.4) \%$ for BOD, and 32 ( \pm 0.3$) \%$ for TOC with the highest IM dosage (160 $\left.\mathrm{g} \mathrm{L}^{-1}\right)$ and IM particle size $<1 \mathrm{~mm}$. Although the adsorption efficiency of IM was lower than the adsorption efficiency obtained with commercial AC (COD removal of $69( \pm 1.7) \%$ with IM dosage of $120 \mathrm{~g} \mathrm{~L}^{-1}$ and particle size $<1 \mathrm{~mm}$ ) the abundance and, under some circumstances, null costs of IM make it worthwhile to search for sorption efficiency improvement. Additionally, a rise of $\mathrm{pH}$ in the solution after treatment with IM is an additional advantage for treating acidic wastewaters. Therefore, the use of IM as sorbent can be seen as an attractive strategy, particularly due to waste availability and waste utilization principles. Based on the experimental data, sorption equilibrium and sorption kinetics of COD removal by IM followed a Freundlich isotherm and pseudo-second-order kinetics. Intra-particle diffusion model indicates that pore diffusion is not the sole rate-controlling step.

Leaching of trace elements (e.g., $\mathrm{Cr}$ and $\mathrm{Zn}$ ) from IM should be taken into consideration, before using Isopropyl Myristate as a sorbent material for wastewater treatment. Investigation with an adsorption column is also recommended before large-scale implementation.

\section{Acknowledgments}

This research was supported by the School of Natural Science, Linnaeus University, Kalmar, Sweden and Department of Sanitary and Environmental Engineering, Rio de Janeiro State University-UERJ, Rio de Janeiro, Braziland. The valuable comments from anonymous reviewers were highly appreciated.

\section{Conflict of Interest}

The authors have declared no conflict of interest.

\section{References}

1. MM Nassar, MF Hamoda, GH Radwan (1995) Adsorption equilibria of basic dyestuff onto palm-fruit bunch particles. Water Sci Technol 32: 27-32.

2. RR Bansode, JN Losso, WE Marshall, RM Rao, RJ Portier (2004) Pecan shell-based granular activated carbon for treatment of chemical oxygen demand (COD) in municipal wastewater. Bioresour Technol 94: 129-135.

3. R Devi, RP Dahiya (2006) Chemical oxygen demand (COD) reduction in domestic wastewater by fly ash and brick kiln ash. Water Air Soil Pollut 174: 33-46.

4. R Devi, RP Dahiya (2008) COD and BOD removal from domestic wastewater generated in decentralized sectors. Bioresour Technol 99: 344-349.

5. WL Sun, YZ Qu, Q Yu, JR Ni (2008) Adsorption of organic pollutants from coking and papermaking wastewaters by bottom ash. J Hazard Mater 154: 595-601.

6. B Hegazy, MA El-Khateeb, A El-adly Amira, MM Kamel (2007) Low-cost wastewater treatment technology. J Appl Sci 7: 815-819.

7. D Mohan, KP Singh, VK Singh (2008) Wastewater treatment using low cost activated carbons derived from agricultural byproducts-A case study. J Hazard Mater 152: 1045-1053.

8. AK Parande, A Sivashanmugam, H Beulah, N Palaniswamy (2009) Performance evaluation of low cost adsorbents in reduction of COD in sugar industrial effluent. J Hazard Mater 168: 800-805.

9. F Kaczala, M Marques, W Hogland (2009) Lead and vanadium removal from a real industrial wastewater by gravitational settling/sedimentation and sorption onto Pinus sylvestris sawdust. Bioresour Technol 100: 235-243.

10. R Devi, V Singh, A Kumar (2008) COD and BOD reduction from coffee processing wastewater using Avacado peel carbon. Bioresour Technol 99: 1853-1860.

11.KR Ramakrishna, T Viraraghavan (1997) Dye removal using low cost adsorbents. Water Sci Technol 36: 189-196.

12.KS Kim, HC Choi (1998) Characteristics of adsorption of rice-hull activated carbon. Water Sci Technol 38: 95-101. 
13.Laymans Report (2003) Regular recycling of wood ash to prevent waste production: RecAsh - A life-environment demonstration project. European Community.

14.T Chirenje, LQ Ma, L Lu (2006) Retention of Cd, Cu, $\mathrm{Pb}$ and $\mathrm{Zn}$ by Wood Ash, Lime and Fume Dust. Water Air Soil Pollut 171: 301-314.

15.M Malakootian, A Almasi, H Hossaini (2008) Pb and Co removal from paint industries effluent using wood ash. Int J Environ Sci Tech 5: 217-222.

16.N Tantemsapya, W Wirojanagud, S Sakolchai (2004) Removal of color, COD and lignin of pulp and paper wastewater using wood ash. Songklanakarin J Sci Technol 26: 1-12.

17.AO Eremina, VV Golovina, M Yu Ugai, AV Rudkovskii (2004) Activated carbons from waste wood in wastewater treatment to remove surfactants. Russ J Appl Chem 77: 775-778.

18.P Leechart, W Nakbanpote, P Thiravetyan (2009) Application of 'waste' wood-shaving bottom ash for adsorption of azo reactive dye. J Environ Manage 90: 912-920.

19.Adamson W Arthur, Gast P Alice (1958) Physical chemistry of surfaces. 393.

20. Y Ho, G McKay (1999) Pseudo-second order model for sorption processes. Process Biochem 34: 451-465.

21.WJ Weber, JC Morris (1963) Kinetics of adsorption onto carbon from solutions. Journal of Sanitary Engineering Division ASCE 89: 31e60.

22.G McKay, MS Otterburn, AG Sweeney (1980) The removal of colour from effluent using various adsorbents -III. Silica: Rate processes. Water Research 14: 15-20.

23.Swedish Standards Institute (2002) Characterization of waste-leaching-compliance test for leaching of granular waste materials and sludge. Part 2: One stage batch test at a liquid to solid ratio of $10 \mathrm{l} / \mathrm{kg}$ for materials with particle size below $4 \mathrm{~mm}$ (with or without Size Reduction). SS-EN 12457-2, Stockholm.

24.LS Clescerl, AE Greenberg, AD Eaton (1999) Standard methods for the examination of water and wastewater. (20 th edn), American Public Health Association/ American Water Works Association/Water Environment Federation, Washington DC, USA.

25.ISO (1989) Water quality-determination of Biochemical Oxygen Demand after $\mathrm{n}$ days (BODn). Part 1: Dilution and seeding method with allylthiourea addition. International Organization for Standardization 5815, Geneva.
26.A Papadopoulos, G Parissopoulos, F Papadopoulos, A Karteris (2001) Variation of COD/BOD5 ratio at different units of a wastewater stabilization pond pilot treatment facility. $7^{\text {th }}$ International Conference on Environmental Science and Technology Ermoupolis, Syros Island, Greece.

27. MAO Badmus, TOK Audu (2009) Periwinkle shell: Based granular activated carbon for treatment of chemical oxygen demand (COD) in industrial wastewater. Can J Chem Eng 87: 69-77.

28. Y Satyawali, M Balakrishnan (2007) Removal of color from biomethanated distillery spentwash by treatment with activated carbons. Bioresour Technol 98: 2629-2635.

29.K Saritpongteeraka, S Chaiprapat (2008) Effects of $\mathrm{pH}$ adjustment by parawood ash and effluent recycle ratio on the performance of anaerobic baffled reactors treating high sulfate wastewater. Bioresour Technol 99: 8987-8994.

30.M Fan, RC Brown, TD Wheelock, AT Cooper, M Nomura, et al. (2005) Production of a complex coagulant from fly ash. Chem Eng J 106: 269-277.

31.J Febrianto, AN Kosasih, J Sunarso, YH Ju, N Indraswati, et al. (2009) Equilibrium and kinetic studies in adsorption of heavy metals using biosorbent: A summary of recent studies. J Hazard Mater 162: 616-645.

32. Hamdaoui, E Naffrechoux (2007) Modeling of adsorption isotherms of phenol and chlorophenols onto granular activated carbon: Part I. Two-parameter models and equations allowing determination of thermodynamic parameters. J Hazard Mater 147: 381-394.

33.OS Amuda, AO Ibrahim (2006) Industrial wastewater treatment using natural material as adsorbent. Afr J Biotechnol 5: 1483-1487.

34.C Hinz (2001) Description of sorption data with isotherm equations. Geoderma 99: 225-243.

35.JC Igwe, AA Abia (2007) Equilibrium sorption isotherm studies of $\mathrm{Cd}(\mathrm{II}), \mathrm{Pb}(\mathrm{II})$ and $\mathrm{Zn}(\mathrm{II})$ ions detoxification from waste water using unmodified and EDTA-modified. Electron J Biotechnol 10: 536-548.

36.AE Ofomaja, EB Naidoo, SJ Modise (2010) Kinetic and pseudo-second-order modelling of lead biosorption onto pine cone powder. Ind Eng Chem Res 49: 25622572.

37.YS Ho, AE Ofomaja (2006) Pseudo-second-order model for lead ion sorption from aqueous solutions onto palm kernel fiber. J Hazard Mater 129: 137-142.

38.ID Mall, VC Srivastava, NK Agarwal (2006) Removal 
of Orange-G and Methyl Violet dyes by adsorption onto bagasse fly ash-kinetic study and equilibrium isotherm analyses. Dyes Pigm 69: 210-223.

39.PN Palanisamy, P Sivakumar (2009) Kinetic and isotherm studies of the adsorption of Acid Blue 92 using a low-cost non-conventional activated carbon. Desalination 249: 388-397.

40.KP Schwandt (1999) Treatment of wood ash contain- ing soluble chromate. Biomass Bioenergy 16: 447462.

41. KP Schwandt, T Salthammer, R Marutzky (2002) Reduction of soluble chromate in wood ash by formaldehyde. Biomass Bioenergy 22: 139-143.

42.S Liodakis, M Tsoukala, G Katsigiannis (2009) Laboratory study of leaching properties of mediterranean forest species ashes. Water Air Soil Pollut 203: 99-107. 